Canadian

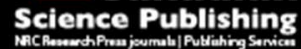

Canadian Journal of Microbiology Revue canadienne de de microbiologie

\title{
Potential to breed for mycorrhizal association in durum wheat
}

\begin{tabular}{|r|l|}
\hline Journal: & Canadian Journal of Microbiology \\
\hline Manuscript ID & cjm-2014-0598.R2 \\
\hline Manuscript Type: & Article \\
\hline Complete List of Authors: & $\begin{array}{l}\text { Ellouze, Walid; Semiarid Prairie Agricultural Research Centre, AAFC; } \\
\text { Alberta Agriculture and Foresty, Crop Diversification Centre South } \\
\text { Hamel, Chantal; Semiarid Prairie Agricultural Research Centre, AAFC } \\
\text { De Pauw, Ron; Semiarid Prairie Agricultural Research Centre, AAFC } \\
\text { Knox, Ron; Semiarid Prairie Agricultural Research Centre, AAFC } \\
\text { Cuthbert, Richard; Semiarid Prairie Agricultural Research Centre, AAFC } \\
\text { Singh, Asheesh; Iowa State University, Agronomy }\end{array}$ \\
\hline Keyword: & \begin{tabular}{l} 
durum wheat, arbuscular mycorrhizal symbiosis, growth response \\
\hline
\end{tabular} \\
\hline
\end{tabular}


3 Walid Ellouze $^{1,2}$, Chantal Hamel ${ }^{1 *}$, R.M. DePauw ${ }^{1}$, R.E. Knox ${ }^{1}$, Richard D. Cuthbert ${ }^{1}$, Asheesh K. Singh ${ }^{1,3 *}$

$5 \quad{ }^{1}$ Semiarid Prairie Agricultural Research Centre, Agriculture and Agri-Food Canada, P.O. Box 1030, 1

6 Airport Road E., Swift Current, Saskatchewan, Canada S9H 3X2

$7 \quad{ }^{2}$ Crop Diversification Centre South, Alberta Agriculture and Foresty, 301 Horticultural Station Road

8 East, Brooks, Alberta, Canada T1R 1E6

$9{ }^{3}$ Department of Agronomy, Iowa State University, 1501 Agronomy Hall, Ames, Iowa 50011, USA

10

$11 *$ Corresponding authors:

12 Chantal Hamel, E-mail: Chantal.Hamel@agr.gc.ca

13 Asheesh K. Singh, E-mail: Singhak@iastate.edu 
15 Abstract

16 The selection of genotypes under high soil fertility may have altered the effectiveness of mycorrhizal

17 symbioses naturally forming between crop plants and the mycorrhizal fungi residing in cultivated fields.

18 We tested the hypothesis that the mycorrhizal symbiosis of five landraces function better than the

19 mycorrhizal symbiosis of 27 cultivars of durum wheat bred after the development of the fertilizer

20 industry. We examined the development of mycorrhiza and the response of these genotypes to mycorrhiza

21 formation after four weeks of growth under high and low soil fertility levels in the greenhouse. The

22 durum wheat genotypes were seeded in an established extraradical hyphal network of Rhizophagus

23 irregularis and in a control soil free of mycorrhizal fungi. The percentage of root length colonized by

24 mycorrhizal fungi was lower in landraces $(21 \%)$ than in cultivars $(27 \% ; P=0.04)$ and in the most recent

25 releases $(29 \% ; P=0.02)$, which were selected under high soil fertility levels. Plant growth response to

26 mycorrhiza varied from $-36 \%$ to $+19 \%$. Overall, durum wheat plant breeding in Canada has increased the

27 mycorrhizal development in wheat grown at low soil fertility level. However, breeding had inconsistent

28 effects on mycorrhizal development and has led to the production of cultivars with patterns of regulation

29 ranging from unimproved to inefficient.

31 Keywords: durum wheat, arbuscular mycorrhizal symbiosis, growth response. 


\section{Introduction}

34 Climate variability threatens food security, the human population continues to grow, and the price of

35 fertilizers continues to rise. A paradigm shift in concepts about plant nutrition can address future challenges by harnessing the potential of arbuscular mycorrhizal (AM) fungi. The AM fungi are ubiquitous soil fungi that spontaneously develop a symbiotic organ called 'mycorrhiza' with the roots of most land plant species, including wheat. These AM symbioses improve the efficiency of nutrients (Mäder et al. 2011) and the tolerance of plants to stresses (Ellouze et al. 2008) by improving the ability of plants to extract soil nutrients and water.

Mycorrhiza formation is generally beneficial to plants, but highly variable plant growth response to AM

42 fungi has shown that AM symbioses range from mutualistic to parasitic associations (Johnson and

43 Graham 2013). The genotype of the plant involved in an AM symbiosis influences the function of the mycorrhiza. Wheat derives less benefit from AM relationships than other crop plants (Plenchette et al. 1983; Ryan and Kirkegaard 2012). However, the genetic variability observed in the compatibility of durum wheat (Triticum turgidum L. var. durum Desf.) with AM fungi (Singh et al. 2012) suggests the

47 potential for improvement of the mycorrhizal association of this important crop plant through conventional breeding practices. Enhancement of mutualistic symbiosis in wheat would result in less dependence on fertilizers, tolerance to environmental stress better than current cultivars, and thereby

50 improve the sustainability of cropping systems.

51 Wheat has been subjected to intensive selection since the Green Revolution, and this selection was largely

52 conducted in soil amended with inorganic fertilizers, which were developed after World War II

53 (Paungfoo-Lonhienne et al. 2012). High soil fertility renders the AM symbiosis unnecessary and

54 suppresses mycorrhiza formation (Johnson and Graham 2013). Thus, the genotypes selected in highly

55 fertile soil for high productivity may or may not have the ability to form an effective AM symbiosis. It

56 has been proposed that modern breeding practices produce wheat cultivars that are highly dependent on 
57 fertilizer supply and are unresponsive to mycorrhiza (Hetrick et al. 1992, 1993; Zhu et al. 2001), but this 58 conclusion is not always supported (Lehmann et al. 2012; Singh et al. 2012). Our objective was to clarify 59 the influence of the selection of genotypes under high soil fertility on the regulation and response of 60 durum wheat to mycorrhiza. We conducted a greenhouse experiment with five landraces brought into 61 Canada prior to 1920 and 27 improved durum wheat cultivars released after 1957 in North America. We

62 hypothesized that landraces, which were populations selected under in situ organic nutrient input 63 conditions, respond and regulate their AM symbiosis better than modern wheat cultivars, which were 64 selected under increasingly high inorganic soil fertility conditions. Changes in the above ground biomass 65 and concentrations of $\mathrm{N}, \mathrm{P}$, and $\mathrm{K}$ were used to describe the response of the durum wheat genotypes to 66 mycorrhiza, and secondly the change in the level of AM root colonization upon exposure to high and low 67 soil fertility levels was used as an indicator of regulation of the symbiosis by the plants.

\section{Materials and methods}

Experimental design, plant material and plant growth conditions

72 The experiment was arranged in a randomized complete block with four replicates, in a greenhouse. The

73 blocking factors were a strong airflow, running from the east to the west side of the greenhouse bench,

74 and time. Blocks 1 and 2 were set up first, and blocks 3 and 4 were set up subsequently to distribute the

75 workload. The 128 treatments were factorial combinations of 32 durum wheat genotypes, two symbiotic

76 status (AM and non-AM), and two fertility conditions (low and high). The durum wheat varieties used

77 were a set of five landraces brought to Canada prior to 1920 (Knott 1995) and a historical set of 27

78 cultivars produced using modern breeding practices i.e., through crossing and progeny selection. The

79 modern cultivars were primarily developed in Canada (Clarke et al. 2010), except 'Quilafen', developed

80 in Chile, and the cultivars 'Ramsey' and 'Lakota', developed at North Dakota Agricultural Research 
81 Station. The seven recent releases (2004-2010) were chosen to represent cultivars selected under a high

82 level of soil fertility for a dryland cropping system. These cultivars were selected under conditions of soil

83 nutrient targets at planting of 100-120 kg ha ${ }^{-1}$ nitrogen, $60 \mathrm{~kg} \mathrm{ha}^{-1}$ phosphorous and $20 \mathrm{~kg} \mathrm{ha}^{-1}$ sulphur

84 (DePauw et al. 2011); potassium was not added as the soil test levels were higher than required for wheat

85 production. The recommended level of fertilization was raised in the 1990's when the average protein

86 content of the Canadian durum wheat crop had dropped and was affecting commercial acceptance. In the

87 mid-1990's, the fertility levels used in the breeding nurseries increased from $60 \mathrm{~kg} \mathrm{~N}^{-1}$ to 100 to 120

$88 \mathrm{~kg} \mathrm{ha}^{-1} \mathrm{~N}$ (DePauw personal communication), and therefore, the cultivars released after 2003 would have

89 been selected under much higher soil $\mathrm{N}$ status.

90 Six surface sterilized seeds of each durum wheat genotype were sown in 1-L pots. One week after

91 emergence, plants were thinned to one per pot. A mycelial network is the functional element of AM fungi

92 (Kabir 2005). In a western Canadian field situation, because no-till is practiced, wheat seeds grow within an AM mycelial network. Thus in this experiment, wheat was sown in a pre-established extraradical AM fungal mycelial network achieved by using lentil (Lens culinaris) as the mother plant to support the development of the extraradical AM fungal mycelial network in experimental pots. Lentil was chosen because it is the most common crop preceding durum wheat in Canadian. Lentil and durum wheat seeds

97 were surface sterilized by soaking for five minutes in $10 \%$ bleach solution (final concentration $0.53 \%$

$98 \mathrm{NaOCl}$ ) containing $0.1 \%$ Tween 20 , and were rinsed with distilled water three times. Eleven weeks prior 99 to seeding durum wheat, six surface sterilized seeds of lentil cultivar 'CDC Glamis' were sown in the 1-L 100 pots filled with 0.95 - $\mathrm{L}$ of pasteurized soil mix $\left(90{ }^{\circ} \mathrm{C}\right.$ for $\left.3 \mathrm{~h}\right)$. The mixture of field soil and sand $(1: 1)$ 101 contained $16.18 \mathrm{mg} \mathrm{kg}^{-1} \mathrm{NO}_{3}-\mathrm{N}$ and $7.63 \mathrm{mg} \mathrm{kg}^{-1} \mathrm{PO}_{4}-\mathrm{P}$ after pasteurization, as per the sodium 102 bicarbonate extraction method (Olsen et al. 1954). Pasteurized soil was mixed with live or autoclaved (30 $103 \mathrm{~min}$ at $130{ }^{\circ} \mathrm{C}, 138 \mathrm{kPa}$ ) AM inoculant in order to provide 165 spores per $100 \mathrm{~g}$ of soil and placed $3 \mathrm{~cm}$ 104 below the lentil seeds in each pot. The AM inoculant was MYKE® PRO GR (Premier Tech 105 Biotechnologies, Rivière-du-Loup, Quebec, Canada), a granular inoculant containing 110 axenically 
produced infective propagules of R. irregularis (syn. Glomus intraradices) per gram of product. This commercial inoculant has long been used in horticultural crops and is used in field crops, including wheat, in the Canadian prairie since 2009. The bottom of the pots was perforated and lined with nylon window screen to prevent soil loss through drainage holes. Lentil plants were grown for eight weeks before watering was stopped. Pots were left to dry for three weeks before cutting the shoots at ground level and seeding wheat seeds as described previously.

112 Lentil and durum wheat plants were examined daily and watered as needed. Once lentil plants expressed 113 signs of deficiency (yellowing of older leaves), usually on a weekly interval, they received $45 \mathrm{~mL}$ of 114 Long Ashton nutrient solution (Hewitt 1966) containing (in $\mathrm{mg} \mathrm{L}^{-1}$ ) $750 \mathrm{KNO}_{3}, 950 \mathrm{Ca}\left(\mathrm{NO}_{3}\right)_{2} \cdot 4 \mathrm{H}_{2} \mathrm{O}$, $115200 \mathrm{NaH}_{2} \mathrm{PO}_{4} \cdot \mathrm{H}_{2} \mathrm{O}, 244 \mathrm{MgSO}_{4}, 520 \mathrm{CaCl}_{2} \cdot \mathrm{H}_{2} \mathrm{O}, 1.7 \mathrm{MnSO}_{4}, 0.25 \mathrm{CuSO}_{4} \cdot 5 \mathrm{H}_{2} \mathrm{O}, 0.30 \mathrm{ZnSO}_{4} \cdot 7 \mathrm{H}_{2} \mathrm{O}, 3.0$

$116 \mathrm{H}_{3} \mathrm{O}_{3}, 5.0 \mathrm{NaCl}, 0.09\left(\mathrm{NH}_{4}\right)_{6} \mathrm{Mo}_{7} \mathrm{O}_{24} \cdot 4 \mathrm{H}_{2} \mathrm{O}$, and $32.9 \mathrm{NaFe}-E D T A$. All lentil plants received the same 117 amount of nutrient solution. Wheat plants under the high fertility regime received $45 \mathrm{~mL}$ of the modified 118 Long Ashton nutrient solution once per week and plants under the low fertility regime received $45 \mathrm{~mL}$ of 119 a $25 \%$ Long Ashton nutrient solution. The day/night temperature was $19 / 15 \pm 2{ }^{\circ} \mathrm{C}$ and the photoperiod 120 was $16 \mathrm{~h}$.

122 Harvest and data collection

123 Four weeks after seeding, durum wheat shoots were cut at ground level, and dried at $45^{\circ} \mathrm{C}$ until constant 124 weight, and dry plant biomass was recorded. Dry shoot tissues were ground in a Thomas Wiley mill 125 (model 4, Thomas Scientific, USA) and digested in $\mathrm{H}_{2} \mathrm{SO}_{4} / \mathrm{Se} / \mathrm{Na}_{2} \mathrm{SO}_{4}$ (Varley 1966). Digests to 126 determine $\mathrm{N}$ and $\mathrm{P}$ concentrations were measured on a segmented flow auto-analyzer (Technicon, AAII 127 System, Tarrytown, New York), and K concentrations were determined on an atomic absorption 128 spectrophotometer (Z-8200 Polarized Zeeman, Hitachi, Japan). 
129 Roots were washed thoroughly, cut into 1-cm fragments, and dispersed and mixed in water. One root 130 sample was taken from each root system and placed in labeled plastic cassettes. Root samples were 131 cleared in $10 \% \mathrm{KOH}$ and stained using an ink and vinegar solution (Vierheilig et al. 1998). The 132 percentage of root colonization by AM fungi was determined using the gridline-intersect method 133 (Giovannetti and Mosse 1980) under a dissecting microscope. Essentially, zones of the root cortex 134 defined by the intersection of 100 randomly distributed roots and the grid-lines of a gridded Petri dish 135 were observed, and the number of zones where AM fungal structures were present was recorded.

137 Statistical analysis

138 The significance of treatment effects on shoot dry mass, nitrogen, phosphorus and potassium was 139 assessed by analysis of variance using JMP v.6 (SAS Institute, Cary, NC, USA). The block effect was set 140 as random, and durum wheat genotype, AM symbiotic status, and soil fertility treatments were set as 141 fixed effects. The significance of the differences between treatment means was assessed using the 142 LSMeans Student's t tests. Contrast analysis was used to compare the group of landraces (pre-1920) with 143 each group of durum wheat cultivars i.e., all cultivars (1957-2010) and the most recent releases (2004144 2010). Analysis of residuals was conducted on the data to identify and remove outliers; the data were 145 tested for normality using the Shapiro-Wilk test. A Log transformation was applied to the values of N 146 concentration to meet the requirement of normality of the test before analysis. The values of $\mathrm{P}$ 147 concentration were normalized by square root transformation and the values of $\mathrm{K}$ concentration were 148 normalized by square transformation. The transformed data were back transformed for data presentation. 149 The significance of the genotype effect on AM root colonization was analyzed using the data from the 150 mycorrhizal treatment only, because as expected all non-mycorrhizal plants were examined and exhibited 151 zero percent mycorrhizal colonization.

152 The nutritional response of durum wheat to mycorrhiza was calculated as: 
Response $M=$ concentration of $M_{(\mathrm{AM})}$ - concentration of $M_{\text {(non-AM) }}$

154 where "response $M$ ' is the nutritional response of a durum wheat genotype for the major nutrient $M$,

155 "concentration of $M_{(\mathrm{AM})}$ " is the concentration of major nutrient $\mathrm{M}$ in the shoot tissue of the AM plant and

156 "concentration of $M_{\text {(non-AM)" }}$ is the concentration of major nutrient $M$ in the shoot tissue of the

157 corresponding non-AM control.

158 The growth response of wheat genotypes to mycorrhiza was calculated as:

159 Growth response $={\text { shoot } \text { biomass }_{(\mathrm{AM})}-\text { shoot }_{\text {biomass }}(\text { non-AM) }}$

160 where "shoot biomass $(\mathrm{AM})$ " is the biomass of the AM plant and "shoot biomass(non-AM)" is the biomass of

161 the corresponding control plant. Redundancy analysis (RDA) was conducted with the rdaTest application

162 (Legendre and Durand 2010) within the R Project for Statistical Computing version 2.15.1 to test the

163 relationship between the multivariate response variables: response- $\mathrm{N}$, response-P, and response-K of

164 durum wheat tissues, and the explanatory variables: growth response and AM root colonization level. The

165 explanatory and response variables (growth response and AM root colonization level) were standardized

166 using the Hellinger transformation in the function 'decostand' in the vegan-package prior to analysis

167 because some of these variables were expressed in different units or had different order of magnitude.

\section{Results and discussion}

170 AM root colonization was significantly affected by fertility but not by genotype (Table 1). There were 171 significant differences among genotypes for dry mass, phosphorous and potassium concentrations in the 172 plant tissue. AM status resulted in significant differences for dry mass and concentration of N, P, and K.

173 There was only one significant interaction detected. An AM status $\times$ fertility interaction (Table $1, P=$

174 0.02) for above ground tissue P concentration indicated that the AM symbiosis, as expected, increased

175 plant tissue P concentration to a larger extent at low soil fertility (mycorrhizal plants: $4.1 \mathrm{mg} \mathrm{g}^{-1}$; control:

$176 \quad 3.7 \mathrm{mg} \mathrm{g}^{-1}$ ) than at high soil fertility level (mycorrhizal plants: $3.5 \mathrm{mg} \mathrm{g}^{-1}$; control: $3.3 \mathrm{mg} \mathrm{g}^{-1}$ ). 
177 Soil fertility levels influenced plants' AM root colonization $(P=0.002)$ from $12 \%$ to $43 \%$ of the root

178 length across genotypes, under low fertility conditions, and from $11 \%$ to $30 \%$, under high fertility

179 conditions (Fig. 1 and Table 1). Under high soil fertility conditions, the level of AM root colonization of 180 the landraces (mean across landraces $=17 \%)$, cultivars $(22 \%)$, and most recent releases $(21 \%)$ was similar $181(P=0.22)$. However, under low soil fertility the landraces developed lower level of AM root colonization $182(21 \%)$ than the modern $(27 \%, P=0.04)$ and most recent cultivars $(29 \%, P=0.02)$, which were 183 developed under conditions of high soil fertility. Overall, modern breeding methods influenced the 184 regulation of the AM symbiosis of wheat, but this influence was inconsistent, leading to the release of 185 cultivars with good, but unimproved regulation and those with impaired AM symbiotic regulation. Under 186 low soil fertility conditions, the cultivars, Commander and Pathfinder, had the highest levels of 187 colonization, while under high fertility conditions, their levels of colonization were reduced (Fig. 1). 188 Reducing investment in AM fungal growth is an appropriate response in eutrophic conditions where the 189 AM symbiosis provides no nutritional benefits. Hercules was the only cultivar to express significantly higher root colonization at high fertility compared to low fertility (Fig 1), which is an inappropriate response to the AM fungi (Johnson and Graham 2013) and is considered an impaired AM symbiotic 192 regulation.

193 Overall, mycorrhizal durum wheat had reduced $(P=0.002)$ shoot dry mass, as compared to the non194 inoculated controls (Table 2), and this reduction was significant for cultivars Hercules, Wascana and 195 Eurostar under low soil fertility conditions (Fig. 2). However, the level of AM root colonization and plant 196 growth response to mycorrhiza were unrelated (Fig. 3). The level of AM root colonization provides an 197 evaluation of the compatibility between the host and fungus components of different associations (Utobo 198 et al. 2011), but it is unrelated to the degree of benefit derived from the mycorrhiza (Hassan et al. 2013b; 199 Hetrick et al. 1993; Powell et al. 2009). The plant's benefit from the AM symbiosis results from a carbon200 efficient adjustment (Johnson and Graham 2013) of the complex interplay between the hyphal and the

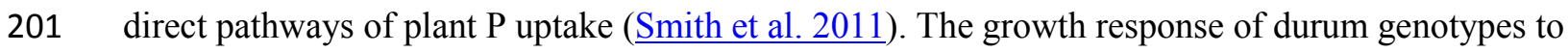


mycorrhiza is a measure of this AM benefit (Reinhart et al. 2012). In this study, mycorrhiza generally had a negative effect on the growth of durum wheat. However, the response of durum wheat to the presence of mycorrhiza may have been underestimated. It is possible that mycorrhizal lentil plants may have drawn more nutrients from the soil than non-mycorrhizal lentil plants. But, the soil conditions were the same for all durum wheat genotypes within an AM status treatment and the possible underestimation to mycorrhizal symbiosis due to lower soil fertility in inoculated pots would have been comparable for all durum wheat genotypes. It was important to establish an AM mycelium network in the designated pots because mycelia are essential functional elements of mycorrhizal symbiosis (Kabir 2005).

The poor response to mycorrhizal symbiosis measured by dry mass in durum wheat genotypes coincided with significantly elevated concentrations of $\mathrm{N}, \mathrm{P}$, and $\mathrm{K}$ in the aboveground tissue of the AM colonized 212 plants compared to non-mycorrhizal controls (Table 2) indicating mycorrhiza function was repressed. 213 High soil fertility conditions resulted in higher concentrations of $\mathrm{N}$ and $\mathrm{K}$ in plant tissues, but in contrast 214 decreased plant $\mathrm{P}$ concentration (Table 2). The AM symbiosis improves plant $\mathrm{P}$ uptake most particularly 215 (Hassan et al. 2013a; Li et al. 2006). This reduction in the concentration of P, accompanied with an increase of other nutrients in durum wheat grown in high fertility conditions is consistent with a dilution

217 effect. The formation and function of the AM symbiosis is regulated by soil fertility. Less carbon is 218 normally invested in mycorrhiza formation and maintenance when nutrients are easily available to roots 219 (Johnson and Graham 2013). High assimilate partitioning to fungal sinks would be an inefficient strategy 220 in rich soils where the AM symbiosis brings no additional benefit to plant nutrition.

221 The growth response and the $\mathrm{N}$ and $\mathrm{K}$ response of durum wheat genotypes to mycorrhiza were inversely 222 related (Fig. 3). When a mycorrhizal treatment genotype grew larger, tissue $\mathrm{N}$ and $\mathrm{P}$ concentrations were 223 diluted. Similar amounts of N, P, and higher amount of K were extracted by mycorrhizal and non224 mycorrhizal plants, but mycorrhizal plants produced less biomass (Table 2), suggesting that mycorrhizal 225 plant growth is carbon rather than nutrient limited. This possibility is supported by a recent report of 226 carbon limitation in Canadian wheat fields with low soil fertility (Dai et al. 2014). The growth response to 
227 mycorrhiza of durum wheat genotypes ranged from positive trends to significant growth depression, 228 which is in agreement with the model of mutualism-parasitism continuum of mycorrhizal function 229 proposed by Johnson and Graham (2013). This model explains that mycorrhiza can depress the growth of 230 their host through the diversion of carbon assimilates from plant sinks (Johnson and Graham 2013). The 231 plants that grow larger with mycorrhiza or to a size similar to that of non-mycorrhizal plants compensate 232 their investment in the maintenance and activity of AM fungi by enhancing their photosynthetic rate 233 (Koide and Elliott 1989). Apparently, the cultivars Hercules, Wascana and Eurostar, could not 234 compensate for the carbon drain accompanying the AM symbiosis and therefore the growth was reduced 235 in the presence of AM fungi compared to the control (Fig. 2). The productivity of cultivars with limited 236 capacity for carbon dioxide assimilation may suffer from mycorrhiza formation, in contrast to cultivars 237 with higher photosynthetic capacity. It might be important to ensure the good regulation and 238 photosynthesis capacity of durum wheat prior to cultivar release, as AM fungi are ubiquitous in 239 commercial fields and can reduce wheat productivity (Dai et al. 2013).

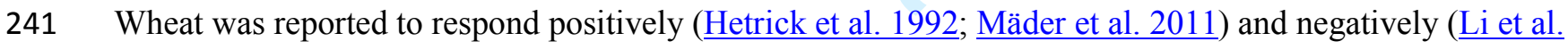
242 2006; Ryan and Kirkegaard 2012) to the AM symbiosis. Growing durum wheat genotypes which support 243 and respond positively to AM symbiosis could provide global benefits to cropping systems (Ellouze et al. 244 2014).

\section{Conclusion}

247 We found little evidence that landraces, which were selected in low soil fertility, respond and regulate 248 their AM symbiosis better than modern wheat cultivars selected under high inorganic soil fertility 249 conditions. Plant breeding had inconsistent effects on AM symbiosis and cultivars with a range of AM 250 symbiosis efficiencies from unimproved to inefficient have been developed. 
We gratefully acknowledge the financial support of the Western Grains Research Foundation. The technical assistance provided by members of SPARC's wheat breeding and soil microbiology research 255 groups is sincerely appreciated.

\section{References}

Clarke, J.M., Clarke, F.R., and Pozniak, C.J. 2010. Forty-six years of genetic improvement in Canadian durum wheat cultivars. Can. J. Plant. Sci. 90(6): 791-801. doi: 10.4141/cjps10091. mycorrhizal fungal communities in rural Canada. Appl Environ Microbiol 79(21): 6719-6729. doi: 10.1128/aem.01333-13. R. 2014. Negative and positive contributions of arbuscular mycorrhizal fungal taxa to wheat production and nutrient uptake efficiency in organic and conventional systems in the Canadian prairie. Soil Biol

267 Biochem 74: 156-166. doi: http://dx.doi.org/10.1016/j.soilbio.2014.03.016.

268 DePauw, R.M., Malhi, S.S., Bullock, P.R., Gan, Y.T., McKenzie, R.H., Larney, F., Janzen, H.H., 269 Cutforth, H.W., and Wang, H. 2011. Wheat Production in Northern High Latitudes - Canadian example. 270 In The World Wheat Book: A History of Wheat Breeding. Edited by W. Angus and A. Bonjean and M. 271 Van Ginkel. Lavoisier Publishing, Paris. pp. 607-651.

272 Ellouze, W., Esmaeili Taheri, A., Bainard, L.D., Yang, C., Bazghaleh, N., Navarro-Borrell, A., Hanson, 273 K., and Hamel, C. 2014. Soil Fungal Resources in Annual Cropping Systems and Their Potential for 274 Management. Biomed Res Int 2014: 15. doi: 10.1155/2014/531824.

275 Ellouze, W., Hanson, K., Nayyar, A., Perez, J., and Hamel, C. 2008. Intertwined existence: The life of 276 plant symbiotic fungi in agricultural soils. In Mycorrhiza : State of the Art, Genetics and Molecular 277 Biology, Eco-Function, Biotechnology, Eco-Physiology, Structure and Systematics. Edited by A. Varma. 278 Springer Berlin Heidelberg. pp. 507-528.

279 Giovannetti, M., and Mosse, B. 1980. An evaluation of techniques for measuring vesicular arbuscular 280 mycorrhizal infection in roots. New Phytol. 84(3): 489-500. 
281

282

283

284

285

286

287

288

289

290

291

292

293

294

295

296

297

298

299

300

301

302

303

304

305

306

307

308

309

310

311

312

313

Hassan, S., Liu, A., Bittman, S., Forge, T., Hunt, D., Hijri, M., and St-Arnaud, M. 2013a. Impact of 12year field treatments with organic and inorganic fertilizers on crop productivity and mycorrhizal community structure. Biol Fertil Soils 49(8): 1109-1121. doi: 10.1007/s00374-013-0813-7.

Hassan, S.E., Hijri, M., and St-Arnaud, M. 2013b. Effect of arbuscular mycorrhizal fungi on trace metal uptake by sunflower plants grown on cadmium contaminated soil. New Biotechnol 30(6): 780-787. doi: http://dx.doi.org/10.1016/j.nbt.2013.07.002.

Hetrick, B.A.D., Wilson, G.W.T., and Cox, T.S. 1992. Mycorrhizal dependence of modern wheat varieties, landraces, and ancestors. Can J Bot 70(10): 2032-2040. doi: 10.1139/b92-253.

Hetrick, B.A.D., Wilson, G.W.T., and Cox, T.S. 1993. Mycorrhizal dependence of modern wheat cultivars and ancestors: a synthesis. Can J Bot. 71(3): 512-518. doi: 10.1139/b93-056.

Hewitt, E.J. 1966. Sand and water culture methods used in the study of plant nutrition. Commonwealth Agricultural Bureau, Farnham Royal, Bucks, England. pp. 431-432.

Johnson, N.C., and Graham, J.H. 2013. The continuum concept remains a useful framework for studying mycorrhizal functioning. Plant Soil 363(1-2): 411-419. doi: 10.1007/s11104-012-1406-1.

Kabir, Z. 2005. Tillage or no-tillage: Impact on mycorrhizae. Canadian Journal of Plant Science 85(1): 23-29. doi: 10.4141/p03-160.

Knott, D.R. 1995. Durum wheat. In Harvest of gold: the history of field crop breeding in Canada. Edited by A.E. Slinkard and D.R. Knott. University Extension Press, University of Saskatchewan, Saskatoon, SK, Canada. pp. 67-81.

Koide, R., and Elliott, G. 1989. Cost, benefit and efficiency of the vesicular-arbuscular mycorrhizal symbiosis. Funct Ecol 3(2): 252-255. doi: 10.2307/2389310.

Legendre, P., and Durand, S. 2010. rdaTest: Canonical redundancy analysis. R package version 1.7. http://adn.biol.umontreal.ca/ numericalecology/Rcode/. Accessed 30 June 2012.

Lehmann, A., Barto, E., Powell, J., and Rillig, M. 2012. Mycorrhizal responsiveness trends in annual crop plants and their wild relatives - a meta-analysis on studies from 1981 to 2010. Plant Soil 355(1): 231-250. doi: 10.1007/s11104-011-1095-1.

Li, H., Smith, S.E., Holloway, R.E., Zhu, Y., and Smith, F.A. 2006. Arbuscular mycorrhizal fungi contribute to phosphorus uptake by wheat grown in a phosphorus-fixing soil even in the absence of positive growth responses. New Phytol 172(3): 536-543. doi: 10.1111/j.1469-8137.2006.01846.x.

Mäder, P., Kaiser, F., Adholeya, A., Singh, R., Uppal, H.S., Sharma, A.K., Srivastava, R., Sahai, V., Aragno, M., Wiemken, A., Johri, B.N., and Fried, P.M. 2011. Inoculation of root microorganisms for sustainable wheat-rice and wheat-black gram rotations in India. Soil Biol Biochem 43(3): 609-619. doi: http://dx.doi.org/10.1016/j.soilbio.2010.11.031. 
Olsen, S.R., Cole, C.V., Watanabe, F.S., and Dean, L.A. 1954. Estimation of available phosphorus in soils by extraction with sodium bicarbonate. U. S. Department of Agriculture, Washington, DC.

Paungfoo-Lonhienne, C., Visser, J., Lonhienne, T.A., and Schmidt, S. 2012. Past, present and future of organic nutrients. Plant Soil 359(1-2): 1-18. doi: 10.1007/s11104-012-1357-6.

Plenchette, C., Fortin, J.A., and Furlan, V. 1983. Growth responses of several plant species to mycorrhizae in a soil of moderate P-fertility. Plant Soil 70(2): 199-209. doi: 10.1007/bf02374780.

Powell, J.R., Parrent, J.L., Hart, M.M., Klironomos, J.N., Rillig, M.C., and Maherali, H. 2009. Phylogenetic trait conservatism and the evolution of functional trade-offs in arbuscular mycorrhizal fungi. Proc. R. Soc. B 276(1676): 4237-4245. doi: 10.1098/rspb.2009.1015.

Reinhart, K.O., Wilson, G.W.T., and Rinella, M.J. 2012. Predicting plant responses to mycorrhizae: integrating evolutionary history and plant traits. Ecol. Lett. 15(7): 689-695. doi: 10.1111/j.14610248.2012.01786.x.

Ryan, M.H., and Kirkegaard, J.A. 2012. The agronomic relevance of arbuscular mycorrhizas in the fertility of Australian extensive cropping systems. Agric. Ecosyst. Environ. 163(0): 37-53. doi: http://dx.doi.org/10.1016/j.agee.2012.03.011.

Singh, A.K., Hamel, C., DePauw, R.M., and Knox, R.E. 2012. Genetic variability in arbuscular mycorrhizal fungi compatibility supports the selection of durum wheat genotypes for enhancing soil ecological services and cropping systems in Canada. Can. J. Microbiol. 58(3): 293-302. doi: 10.1139/w11-140.

Smith, S.E., Jakobsen, I., Grønlund, M., and Smith, F.A. 2011. Roles of arbuscular mycorrhizas in plant phosphorus nutrition: interactions between pathways of phosphorus uptake in arbuscular mycorrhizal roots have important implications for understanding and manipulating plant phosphorus acquisition. Plant Physiol 156(3): 1050-1057. doi: 10.1104/pp.111.174581.

Utobo, E.B., Ogbodo, E.N., and Nwogbaga, A.C. 2011. Techniques for extraction and quantification of arbuscular mycorrhizal fungi. LARCJI 2(2): 68-78.

Varley, J.A. 1966. Automatic methods for the determination of nitrogen, phosphorus and potassium in plant material. Analyst 91(1079): 119-126.

Vierheilig, H., Coughlan, A.P., Wyss, U., and Piche, Y. 1998. Ink and vinegar, a simple staining technique for arbuscular-mycorrhizal fungi. Appl. Environ. Microbiol. 64(12): 5004-5007.

Zhu, Y.G., Smith, S.E., Barritt, A.R., and Smith, F.A. 2001. Phosphorus (P) efficiencies and mycorrhizal responsiveness of old and modern wheat cultivars. Plant Soil 237(2): 249-255. doi: 10.1023/a:1013343811110. 
Table 1 Summary of the probabilities of effects of durum wheat genotype, AM symbiotic status, soil fertility and their interactions on AM root colonization $(\mathrm{Col})$, dry mass, and nitrogen $(\mathrm{N})$, phosphorus $(\mathrm{P})$ and potassium $(\mathrm{K})$ concentrations in plant tissues, according to $\operatorname{ANOVA}(n=4)$

\begin{tabular}{|c|c|c|c|c|c|c|}
\hline Source of variance & $d f$ & $\begin{array}{l}\text { Col } \\
(\%)\end{array}$ & $\begin{array}{c}\text { Dry mass } \\
\text { (g) }\end{array}$ & $\begin{array}{c}\mathrm{N} \\
\left(\mu \mathrm{g} \cdot \mathrm{g}^{-1}\right)\end{array}$ & $\begin{array}{c}P \\
\left(\mu \mathrm{g} \cdot \mathrm{g}^{-1}\right)\end{array}$ & $\begin{array}{c}\mathrm{K} \\
\left(\mu \mathrm{g} . \mathrm{g}^{-1}\right)\end{array}$ \\
\hline Genotype & 31 & $0.8272^{\mathrm{ns}}$ & $0.0373 *$ & $0.8040^{\mathrm{ns}}$ & $<0.0001 * * *$ & $0.0103 *$ \\
\hline AM status & 1 & - & $0.0015^{* *}$ & $0.0146^{*}$ & $<0.0001 * * *$ & $0.0022 * *$ \\
\hline Fertility & 1 & $0.0016^{* *}$ & $<0.0001 * * *$ & $<0.0001 * * *$ & $<0.0001 * * *$ & $<0.0001 * * *$ \\
\hline Genotype $\times$ AM status & 31 & - & $0.7409^{\mathrm{ns}}$ & $0.9109^{\mathrm{ns}}$ & $0.6483^{\mathrm{ns}}$ & $0.6250^{\mathrm{ns}}$ \\
\hline Genotype $\times$ Fertility & 31 & $0.2592^{\mathrm{ns}}$ & $0.3772^{\mathrm{ns}}$ & $0.8483^{\mathrm{ns}}$ & $0.2000^{\mathrm{ns}}$ & $0.9603^{\mathrm{ns}}$ \\
\hline AM status $\times$ Fertility & 1 & - & $0.4801^{\mathrm{ns}}$ & $0.6385^{\text {ns }}$ & $0.0215^{*}$ & $0.8057^{\text {ns }}$ \\
\hline Genotype $\times$ AM status $\times$ Fertility & 31 & - & $0.7433^{\mathrm{ns}}$ & $0.9841^{\mathrm{ns}}$ & $0.7531^{\mathrm{ns}}$ & $0.5602^{\mathrm{ns}}$ \\
\hline
\end{tabular}
level. 
Table 2 Shoot nitrogen, phosphorus and potassium concentrations and above grown biomass production of 4-week old durum wheat plants, as influenced by arbuscular mycorrhiza and soil fertility

\begin{tabular}{lccccccc}
\hline Symbiotic status & $\begin{array}{c}\mathrm{N} \\
\left(\mathrm{m} \mathrm{g} \mathrm{g}^{-1}\right)\end{array}$ & $\begin{array}{c}\mathrm{N} \text { uptake }(\mathrm{mg} \\
\left.\mathrm{plant}^{-1}\right)\end{array}$ & $\begin{array}{c}\mathrm{P} \\
\left(\mathrm{mg} \mathrm{g}^{-1}\right)\end{array}$ & $\begin{array}{c}\text { P uptake } \\
\left(\mathrm{mg} \mathrm{plant}^{-1}\right)\end{array}$ & $\begin{array}{c}\mathrm{K} \\
\left(\mathrm{mg} \mathrm{g}^{-1}\right)\end{array}$ & $\begin{array}{c}\text { K uptake (mg } \\
\left.\text { plant }^{-1}\right)\end{array}$ & $\begin{array}{c}\text { Dry mass } \\
\left(\mathrm{mg} \mathrm{plant}^{-1}\right)\end{array}$ \\
\hline Mycorrhizal & 26.8 & 18.0 & 3.8 & 2.4 & 44.8 & 31.8 & 680 \\
Non-mycorrhizal & 25.7 & 18.5 & 3.5 & 2.3 & 43.2 & 30.7 & 720 \\
$P$ value & $0.0146^{*}$ & $0.1050^{n s}$ & $<0.0001^{* * *}$ & $0.2058^{n s}$ & $0.0022^{* *}$ & $0.0422^{*}$ & $0.0015^{* *}$ \\
\hline
\end{tabular}

\begin{tabular}{lccccccc} 
Fertility $^{Z}$ \\
\hline Higher & 29.1 & 23.3 & 3.4 & 2.8 & 46.2 & 37.7 & 810 \\
Lower & 23.4 & 13.1 & 3.9 & 2.3 & 41.8 & 24.7 & 580 \\
$P$ value & $<0.0001^{* * *}$ & $<0.0047^{* *}$ & $<0.0001^{* * *}$ & $0.0424^{*}$ & $<0.0001^{* * *}$ & $<0.0001^{* * *}$ & $<0.0001^{* * *}$
\end{tabular}

352 ns: non-significant; * significant at the $5 \%$ level; **significant at the $1 \%$ level; ***significant at the $0.1 \%$ 353 level.

$354{ }^{\mathrm{Z}}$ All comparisons between higher and lower fertility levels were made under mycorrhiza treatment. 
357 Fig. 1 The level of AM root colonization (colonized root sections / 100 root sections) of landraces and 358 modern durum wheat cultivars grown in the greenhouse under low or high soil fertility conditions. The 359 most recent cultivars were selected under high soil fertility conditions. Stars indicate a statistically 360 significant difference in colonization levels between low and high fertility conditions for the cultivars 361 Commander, Pathfinder, and Hercules, according to LSMeans Student's $t$ set at $\alpha=0.05(n=4)$. Modern 362 cultivars have higher levels of AM root colonization than landrace, when grown in low fertility conditions $363(P=0.04)$.

Fig. 2 Shoot dry mass of landraces and modern wheat genotypes grown in symbiosis with $R$. irregularis and of non-mycorrhizal controls grown under low soil fertility conditions. Overall, the biomass of

367 symbiotic durum wheat was reduced under low fertility conditions $(P=0.04)$. Stars indicate that the 368 difference between the mycorrhizal and non-mycorrhizal treatments was significant only for the cultivars 369 Eurostar, Wascana, and Hercules, according to LSMeans Student's $t$ set at $\alpha=0.05(n=4)$. The most 370 recent cultivars were selected under high soil fertility conditions.

372 Fig. 3 Redundancy analysis biplot of the multivariate relationship $(P=0.001)$ between the response of 373 leaf tissues N, P, and K concentrations to mycorrhiza, and the level of AM root colonization and growth 374 response to mycorrhiza, in durum wheat (Axes 1 and 2 explain respectively $20.1 \%$ and $1.2 \%$ of the 375 variance). The biplot shows that the P response of the plants is related with the level of AM root 376 colonization, but unrelated to plant growth response. The biplots also shows a negative relationship 377 between the nutritional responses and the growth response of durum wheat. 
Durum wheat cultivar (date of release)

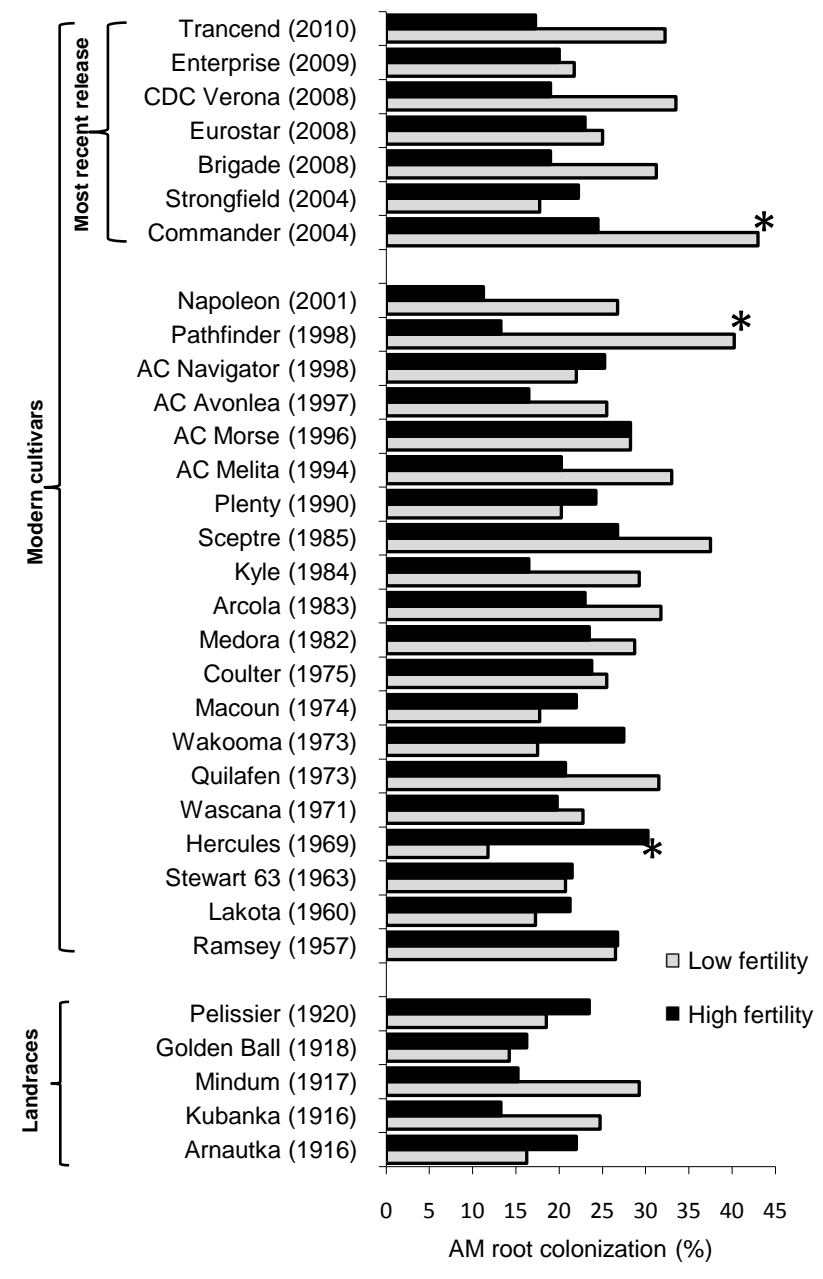

https://mc06.manuscriptcentral.com/cjm-pubs 
Durum wheat cultivar (date of release)

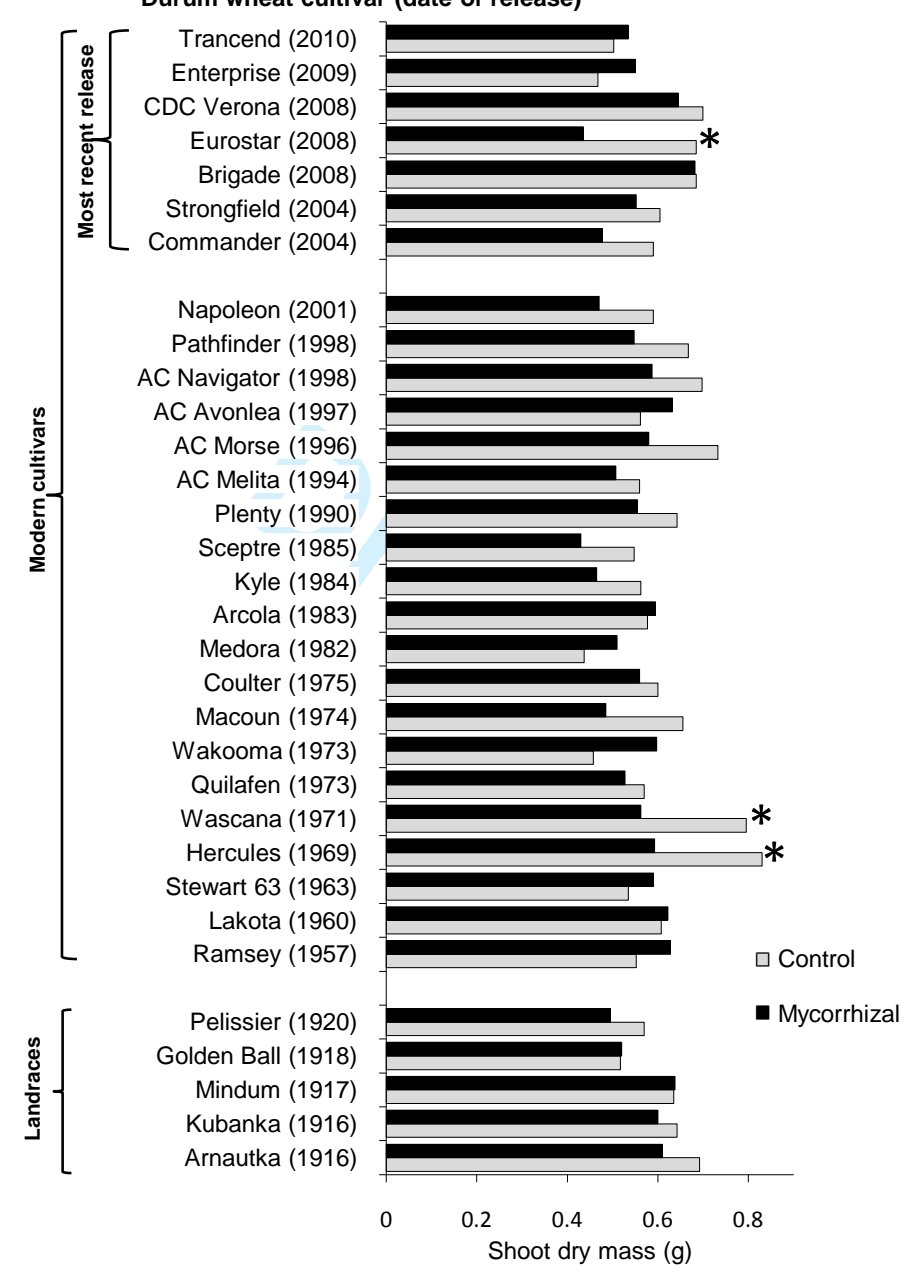

https://mc06.manuscriptcentral.com/cjm-pubs 


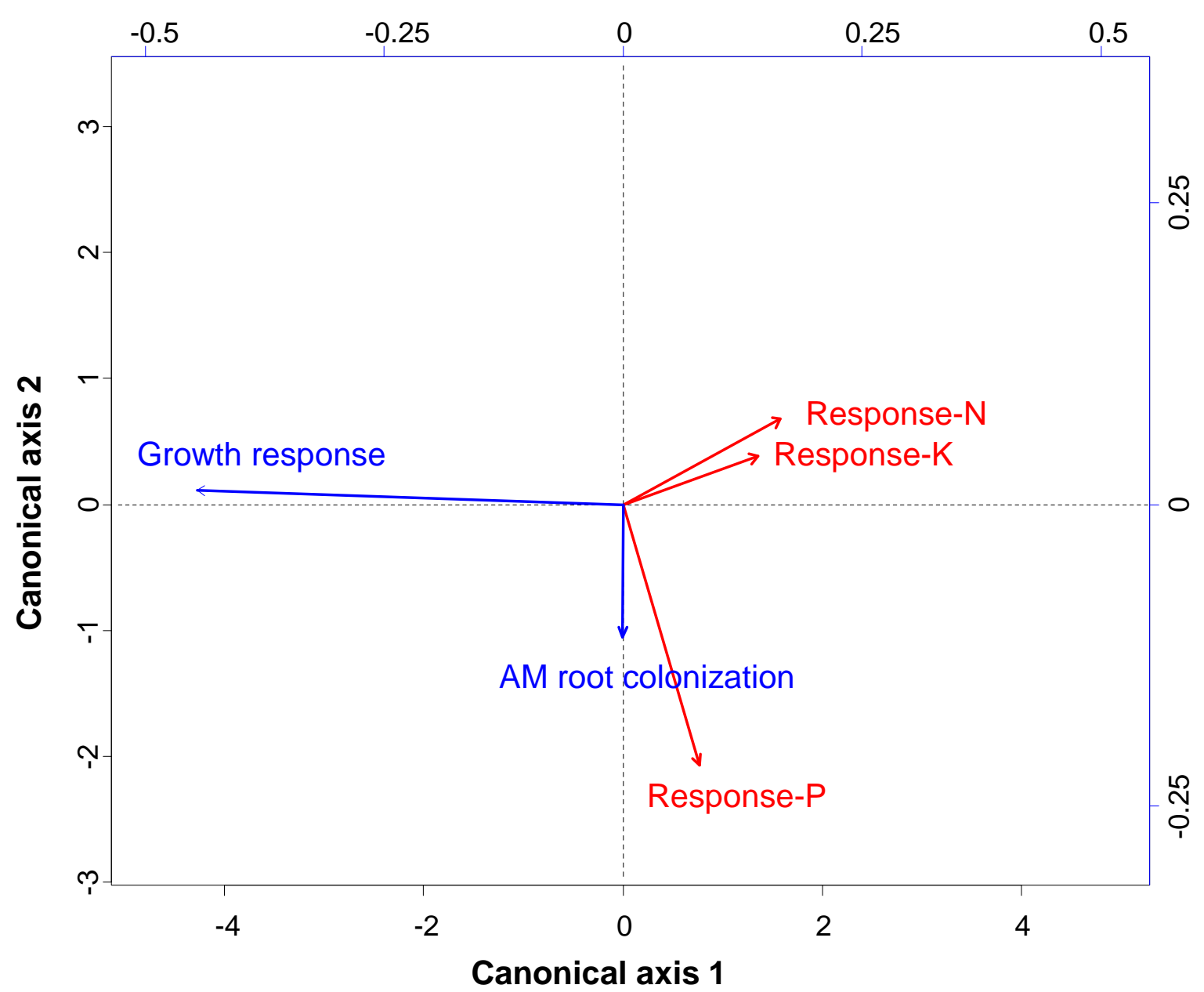

https://mc06.manuscriptcentral.com/cjm-pubs 